The International Economy, Vol. 19, 2016

\title{
Greenhouse-gas Emission Controls and International Carbon Leakage through Trade Liberalization ${ }^{1)}$
}

\author{
Jota Ishikawa \\ Hitotsubashi University and RIETI
}

Toshihiro Okubo

Keio University

\begin{abstract}
Using the footloose capital model with two countries, this paper studies different impacts of emission taxes and quotas on firm location and global emissions under trade liberalization. If only one country (North) sets a target of emissions, firms may have incentive to relocate to the other country (South). That is, the pollution haven effect could arise. We show that a further decrease in trade costs, given an emission regulation in North, increases firm relocation and global emissions only if trade costs are relatively low. Moreover, compared with emission taxes, emission quotas moderate firm relocation, which results in less pollution haven and hence less global emissions.
\end{abstract}

JEL: F18, Q54

Key words: emission taxes, emission quotas, pollution haven, firm relocation, trade liberalization

\section{Introduction}

Global warming is one of the most serious concerns in the current world. A layer of greenhouse gases (GHGs) acts as a blanket of the earth and blocks heat from escaping. Over the last century, global average temperature has increased by more than $0.7^{\circ} \mathrm{C}$. Global warming is expected to cause changes in rainfall and drought patterns, ocean circulation, animal and plant life cycles, and so on. In fact, persistent unusual weather conditions have recently been observed all over the world.

To cope with global warming, an international environmental treaty, the United Nations Framework Convention on Climate Change (UNFCCC), was adopted at the Earth Summit held in Rio de Janeiro in 1992. It entered into force in March 1994 and has been ratified by 196 countries, which constitute the "Parties" to the Convention. Since then, the Conference of Parties to the UNFCCC (COP) has been held every year.

The Kyoto Protocol was adopted at the third session of the COP (COP3) in December 1997. In the protocol, the industrialized countries, which are called Annex I Parties, made a

Received 10 May 2016, Accepted 12 August 2016, Released online in J-STAGE as advance publication 23 September 2016

1) We wish to thank an anonymous referee and seminar participants at RIETI for their helpful comments and suggestions. We acknowledge financial support from the Japan Society for the Promotion of Science through the Grant-in-Aid for Scientific Research (S) Grant Number 26220503. 
Greenhouse-gas Emission Controls and International Carbon Leakage through Trade Liberalization

commitment to decrease their GHG emissions by 5.2\% compared to their 1990 baseline levels over the 2008 to 2012 period. However, the United States, which was a signatory to the protocol, has not ratified the protocol. Furthermore, developing countries such as China and India have no obligation to the reduction. In these circumstances, a serious concern is international carbon leakage. The reduction of GHG emissions in some countries (typically, Annex I Parties) may increase GHG emissions in other countries. As a result, worldwide emissions may rise.

One of the sources of international carbon leakage is firm relocation. In response to different GHG emission regulations among countries, firms may relocate from countries with stringent regulations to countries with lax regulations. This is called the pollution haven hypothesis. ${ }^{2}$ Another source is fuel price changes (e.g., Felder and Rutherford, 1993; Burniaux and Martins, 2000; Ishikawa and Kiyono, 2000; Kiyono and Ishikawa, 2004, 2013). When a country adopts policies to reduce GHG emissions, its demand for fossil fuels is likely to decrease. If the world prices of fossil fuels fall as a result of this decrease in a country attempting to reduce its GHG emissions, the demand for fossil fuels rises in other countries with weak regulations. International carbon leakage may also arise through changes in a country's industrial structures, as shown in Copeland and Taylor (2005) and Ishikawa and Kiyono (2006).

COP18 in Doha in 2012 made amendments to the Kyoto Protocol, in which an 8-year second commitment period starting from 2013 was established. However, Canada, Japan, and Russia were dissatisfied with the amendments and announced their secession from the protocol. Japan was deeply concerned about international carbon leakage with a mere extension of the protocol. ${ }^{3)}$

In COP19 in Warsaw, Parties agreed to communicate their respective contributions towards the universal agreement well in advance of the meeting in Paris in 2015. Then COP21 in Paris made a new international agreement on the climate, which is applicable to all Parties with the aim of keeping global warming below $2{ }^{\circ} \mathrm{C}$ compared with pre-industrial levels. ${ }^{4)}$ The agreement will enter into force in 2020.5) All the UNFCCC Parties have to submit their specific targets of reducing GHG emissions. However, the targets are quite different across Parties. For example, EU's target is a 40\% GHG emission reduction by 2030 compared with 1990 , while China's target is a reduction of CO2 emissions per unit of GDP by $60-65 \%$ by 2030 compared with the 2005 level. ${ }^{6}$ Since China's target is a reduction in terms of per unit of GDP, the emission is expected to keep increasing and reach the maximum in 2030. ${ }^{7}$

2) The related literature is introduced later.

3) In 2012, the total share of CO2 emissions of China, US and India, which are outside of the Kyoto Protocol, was $48.2 \%$. China was the largest emitter (26\%) and US was the second largest emitter $(16 \%)$. EU is the third largest emitter (11\%), but as a single country, India is the third largest emitter $(6.2 \%)$.

4) This aim was set in COP16 in Cancun.

5) As of 29 April 2016, there are 177 signatories to the Paris Agreement.

6) The targets of US, Japan, Russia and Brazil are, respectively, a $26-28 \%$ emission reduction by 2025 compared with 2005, a $26 \%$ emission reduction by 2030 compared with 2013 , a $25-30 \%$ emission reduction by 2030 compared with 1990, and a 37\% emission reduction by 2025 compared with 2005 .

7) India's target is similar to China's. It is a reduction of emissions per unit of GDP by $33-35 \%$ by 2030 compared with the 2005 level. 
J. Ishikawa and T. Okubo

Table 1: Key steps against global warming

\begin{tabular}{|c|c|c|c|}
\hline & $\begin{array}{l}\text { Convention/ } \\
\text { Conference }\end{array}$ & Main outcome & \\
\hline 1992 & Rio Earth Summit & UNFCCC & \\
\hline 1995 & COP1 Berlin & & \\
\hline 1997 & COP3 Kyoto & Kyoto Protocol & \\
\hline 2005 & CMP1 Montreal & & \\
\hline 2007 & COP13 Bali & Bali Road Map & A set of a forward-looking decisions \\
\hline 2009 & COP15 Copenhagen & Copenhagen Accord & Developed countries' promises to fund actions \\
\hline 2010 & COP16 Cancun & Cancun Agreements & $\begin{array}{l}\text { A common goal of limiting global warming to } 2^{\circ} \mathrm{C} \\
\text { compared with pre-industrial levels }\end{array}$ \\
\hline 2011 & COP17 Durban & Durban Platform & Launch of a new platform of negotiations \\
\hline 2012 & COP18 Doha & $\begin{array}{l}\text { Doha Amendment to Kyoto } \\
\text { Protocol }\end{array}$ & $\begin{array}{l}\text { GHG emission reductions by at least } 18 \% \text { below } \\
1990 \text { levels in the eight-year period from } 2013 \text { to } \\
2020\end{array}$ \\
\hline 2013 & COP19 Warsaw & Warsaw Outcomes & $\begin{array}{l}\text { Agreement to communicate contributions towards } \\
\text { the universal agreement well in advance of COP } 21\end{array}$ \\
\hline 2015 & COP 21 Paris & Paris Agreements & $\begin{array}{l}\text { A new international agreement on the climate, appli- } \\
\text { cable to all countries, with the aim of keeping global } \\
\text { warming below } 2^{\circ} \mathrm{C}\end{array}$ \\
\hline
\end{tabular}

UNFCCC: The United Nations Framework Convention on Climate Change

COP: Conference of the Parties to UNFCCC

CMP: Conference of the Parties serving as the meeting of the Parties to the Kyoto Protocol

It should be noted that the targets were submitted under the "pledge-and-review" scheme. That is, each Party unilaterally announces its voluntary action and hence there is no coordination in methods or measurements among Parties. Moreover, this scheme provides Parties with flexibility but lacks credibility, because there are no binding commitments. Thus, Parties may be tempted to renege on their pledges.

In this paper, we explore GHG emission controls in the presence of international carbon leakage through international firm relocation in the footloose capital (FC) model developed by Martin and Rogers (1995). Specifically, we examine the relationship between trade liberalization and international carbon leakage when only North sets a target of GHG emissions. We also compare the consequences emission quotas (including the creation of a competitive emission-permit market) and emission taxes under trade liberalization for firm location and the degree of carbon leakage.

We find that international carbon leakage and hence global emissions become U-shaped in trade freeness under either policy. In the presence of international carbon leakage through firm relocation, given an emission policy in North, trade liberalization first decreases global emissions with high trade costs and then increases them with low trade costs. With low trade costs, therefore, there is a trade-off between unilateral GHG emission controls and trade liberalization. This suggests that in view of the continuation of trade liberalization, South should also be involved in GHG emission controls to cope with global warming.

When the regulation takes the form of an emission quota (with tradable permits), firm relocation reduces the demand for permits in North and hence the permit price falls. An emission tax, which is exogenously fixed, provides no such moderating effect. A quota therefore results in less relocation when compared to an equivalent tax for a given reduction in trade costs. Because firms emit more when they are in unregulated South, regulation by permits 
Greenhouse-gas Emission Controls and International Carbon Leakage through Trade Liberalization

results in unambiguously less global GHG emissions than regulation by taxes in the presence of relocation of industry caused by trade liberalization.

Our study follows the pollution haven hypothesis. In the framework of an open economy, the first theoretical analysis on the hypothesis is Pethig (1976). Then Markusen et al. (1993, 1995 ) investigate the hypothesis in the presence of foreign direct investment (FDI). In Markusen et al. (1993), two polluting firms (one is local and the other is foreign) choose the number of plants and plant locations when only the home country adopts emission taxes. They are primarily concerned with market structures induced by taxes. In Markusen et al. (1995), a single firm decides the plant number and locations when both countries adopt environmental policies non-cooperatively. ${ }^{8)}$ The governments have incentive to lower (raise) environmental standards to attract (deter) investment if the benefit from investment is greater (less) than the loss (i.e., the environmental damage). ${ }^{9)}$

Empirical evidences on the pollution haven hypothesis are mixed. According to Jaffe et al. (1995), differences in environmental policy have little or no effect on trade patterns, investment or firm location. However, by using sectoral data, Ederington et al. (2005) and Cole et al. (2010) find pollution haven effect in some pollution intensive industries. Henderson (1996), Becker and Henderson (2000), Greenstone (2002), and List et al. (2003) find that pollution-intensive plants are responding to environmental regulations. Smarzynska and Wei (2004) discuss factors that may make the evidence of the hypothesis weak. Levinson and Taylor (2008) point out that the pollution haven effects have been underestimated.

Currently there are several studies on environmental policies and pollution haven effect in the framework of trade and geography model (Pflüger, 2001; Venables, 2001; Elbers and Withagen, 2004; Ishikawa and Okubo, 2011, 2016). ${ }^{10)}$ Pflüger (2001), which is a pioneering work, considers Pigouvian emission taxes. However, his analysis is along the line of Markusen et al. (1995). Thus, environmental damages are local and governments can detect emitters, estimate the damage, and impose optimal emission taxes. By contrast, Ishikawa and Okubo (2016) model global emissions and firm location. Since global emissions are almost impossible to identify polluters and estimate emissions damage, the government cannot levy a tax on each polluter and compensate the public through tax reimbursement.

This paper is a companion paper of Ishikawa and Okubo (2016). Ishikawa and Okubo (2016) construct the model with two pollution-intensive monopolistic competition sectors and find that more pollution intensive sector are more sensitive to emission policies than less intensive sector and emission quota results in spatial sorting. While more emission intensive

8) Forslid et al. (2015) construct two-country trade model with monopolistic competition in the presence of endogenous emission taxes and study the relationship between tax rates and market size.

9) When a country adopts exceedingly lax environmental policies in order to keep its competitive advantage, its strategy is sometimes called "environmental (or ecological) dumping." On the other hand, when a country adopts stringent environmental policies in order to reduce local pollution, this strategy is called "Not in my back yard (NIMBY)." There are a number of studies which, following Markusen et al. (1995), analyse environmental dumping and NIMBY. See, for example, Rauscher (1995) and Ulph and Valentini (2001).

10) Venables (2001) studies the impact of an ad valorem tax on equilibrium in a vertical linkage model. In the case of energy taxes that are unilaterally introduced in one country, he discusses hysteresis in location but does not investigate quotas. Elbers and Withagen (2004) study the impact of an emission tax on agglomeration in the presence of labor migration. 
sector concentrates in a country without environmental regulations, less intensive sector is in a country with them. By contrast, this paper models only one pollution sector. Under one pollution sector, we compare pollution haven effects between emission taxes and quotas.

The rest of the paper is organized as follows. In Section 2, we present our basic model. Emission taxes and quotas are investigated in Sections 3 and 4, respectively. Then, in Section 5, we compare emission taxes with emission quotas. Section 6 concludes the paper.

\section{Basic Model}

\subsection{Basic setting without environmental policies}

We basically introduce GHG emissions into the footloose capital model developed by Martin and Rogers (1995). There are two countries (North and South), two production factors (labor, $L$, and physical capital, $K$ ) and two sectors (agriculture: A-sector, and manufacturing: $\mathrm{M}$-sector). North is bigger than South in population size. The agricultural product is produced from labor alone by perfectly competitive firms under CRS technology and is traded without any trade costs. Specifically, one unit of labor is required to produce one unit of the agricultural product. This product serves as a numéraire. The manufactured goods are subject to the Dixit-Stiglitz type of monopolistic competition and are traded with trade costs. Firms in $\mathrm{M}$-sector can move between countries, but there is no entry and exit.

$\mathrm{M}$-sector uses labor and exclusively employs capital. Specifically, each firm is required to use one unit of capital, which represents fixed costs, and " $a$ " units of labor to produce one unit of its product. The cost function for firm $j$ is given by $T C_{j}=\pi+a w x_{j}$, where $\pi$, i.e., the fixed cost, represents capital return; $w$ is the wage rate; and $x_{j}$ is output of firm $j$. M-sector emits GHGs in the process of production. Specifically, the production of one unit of an M product entails one unit of GHG emissions. Trade costs, $\tau(\geq 1)$, are the iceberg type. When $x$ units of good are exported, only $x / \tau$ units arrive because of iceberg trade costs. The freeness of trade, $\phi$, can be defined as $\phi \equiv \tau^{1-\sigma}$ (where $\left.\sigma>1\right)$. This implies that $\phi=1(\tau=1)$ and $\phi=0(\tau=\infty)$, respectively, represent free trade and autarchy. For the sake of simplicity, we assume that the same technology is used in both North and South and no abatement is possible. ${ }^{11}$

Turning to the demand side, a representative consumer in North has the following quasilinear utility function:

$$
U=\ln M+A-f\left(G+G^{*}\right), M \equiv\left(n c^{1-1 / \sigma}+n^{*} c_{S}^{1-1 / \sigma}\right)^{1 /(1-1 / \sigma)}, \sigma>1,
$$

where $M$ and $A$ stand for consumption of $\mathrm{M}$-sector and A-sector varieties, respectively. "*” indicates variables and parameters in South. $n$ is the number of differentiated varieties. $c$ is the quantity of North consumption for each variety produced in North, while $c_{S}$ is the quantity of North consumption for each variety produced in South. ${ }^{12}$ $\sigma$ in the CES function for differentiated varieties denotes the constant elasticity of substitution between two varieties. ${ }^{13)}$ The

11) Even in the presence of different technologies including abatement, the essence of our results would not change.

12) $c_{S}$ should be distinguished from $c^{*}$ which is the quantity of South consumption for each variety produced in North.

13) The equilibrium path in the FC model with a quasi-linear utility function is identical to that of the CobbDouglas utility function. 
disutility is expressed as an increasingly monotonic function of GHG emissions, $f\left(G+G^{*}\right)$, where $G$ is GHG emissions. Each consumer has one unit of capital as well as one unit of labor and gets income from both factors, $w+\pi$. However, the quasi-linear utility function has no income effect and thus each consumer buys a certain number of units of M-goods regardless of her/his income.

Labor is mobile between sectors but immobile between countries. While capital is mobile between North and South, capital owners are immobile and thus capital rewards are repatriated to the country of origin. Because capital endowment is initially allocated in proportion to labor endowment (market size), North's share of initial capital and labor endowments are given by $s_{K} \equiv K / K^{W}=L / L^{W} \equiv s_{L}$, where " $W$ " stands for values pertaining to the world. However, after firms relocate, capital share is generally not equal to population share, whereas population share always corresponds to labor share, $s_{L}$, and capital share is always identical to firm share, $s_{K}=n / n^{W}$. This is because each footloose firm needs one unit of capital. Because no income effect exists, the quasi-linear utility function ensures $s \equiv s_{L}=s_{E}$, where $s_{E} \equiv E / E^{W}$ is the share of North expenditure on $\mathrm{M}$-goods. For simplicity, total labor and capital endowments, $L^{W}$ and $K^{W}$ (thus the total number of firms, $n^{W}$ ), are normalized to one. Thus, $n$ is North's share of firms. ${ }^{14)}$ We should note that $E^{W}=1$ holds with (1).

\subsection{Initial equilibrium}

Since the A-sector good is freely traded internationally, wage rates in both countries are equalized: $w=w^{*}=1$. Utility maximization results in the well-known CES demand function. As a result of maximization, the local and export prices of the product variety of the North-based M-sector firm are given by

$$
p=\frac{a}{1-1 / \sigma}, p^{*}=\frac{\tau a}{1-1 / \sigma} .
$$

The local and export prices of the product variety of the South-based M-sector firm are isomorphic. Consumption per variety for the North-based M-sector firm are:

$$
c=\frac{p^{-\sigma} E}{n p^{1-\sigma}+n^{*} p^{* 1-\sigma}}, c^{*}=\frac{p^{*-\sigma} E^{*}}{n p^{1-\sigma}+n^{*} p^{* 1-\sigma}},
$$

where $c^{*}$ is the quantity of South consumption for each variety produced in North. Similarly, consumption per variety for the South-based $\mathrm{M}$-sector firm are isomorphic. The quantity produced by each North-based firm for the North market is given by

$$
x=\frac{p^{-\sigma} s}{n p^{1-\sigma}+n^{*} p^{* 1-\sigma}}
$$

which is identical to $c$.

Turning to the export market, when $x$ units are exported, only $x / \tau$ units reach the foreign market because of iceberg trade costs. While North's consumption is equal to the quantity produced in North for each variety (i.e., $x=c$ ), the quantity produced for the foreign market is

14) The total number of households (population) is one in the world, because each individual has one unit of labor and capital. The level of demand depends on population size rather than income with a quasilinear utility function. 
$x^{*}=c^{*} \tau=\frac{\tau p^{*-\sigma}(1-s)}{n p^{1-\sigma}+n^{*} p^{* 1-\sigma}}$. It follows that the total quantity produced by a North-based firm, firm $j$, is given by:

$$
x+x^{*}=\left(\frac{s}{n p^{1-\sigma}+n^{*} p^{* 1-\sigma}}+\phi \frac{1-s}{n p^{1-\sigma}+n^{*} p^{* 1-\sigma}}\right) p^{-\sigma} .
$$

Since producing one unit of goods entails one unit of GHG emissions, the amount of local emissions in each country corresponds to each country's total quantity produced. Local emission levels in North and South are respectively:

$$
G \equiv n\left(x+x^{*}\right)=n b\left(\frac{s}{\Delta}+\phi \frac{1-s}{\Delta^{*}}\right) a^{-\sigma}, G^{*} \equiv n^{*} b\left(\phi \frac{s}{\Delta}+\frac{1-s}{\Delta}\right) a^{-\sigma},
$$

where $b \equiv \frac{1}{(1-1 / \sigma)} ; \Delta \equiv n a^{1-\sigma}+\phi(1-n) a^{1-\sigma} ;$ and $\Delta^{*} \equiv \phi n a^{1-\sigma}+(1-n) a^{1-\sigma}$. Since $b$ is exogenously given and constant, without loss of generality, we can normalize $b=1$ by an appropriate choice of units. ${ }^{15)}$ Note that GHG emissions in North and South correspond to quantities produced in each country. In sum, global emissions are $G^{W} \equiv G+G^{*}=$ $n\left(\frac{s}{\Delta}+\phi \frac{1-s}{\Delta}\right) a^{-\sigma}+n^{*}\left(\phi \frac{s}{\Delta}+\frac{1-s}{\Delta}\right) a^{-\sigma}$.

By using (2)-(4), pure profits for a representative firm in North and South are, respectively, given by: ${ }^{16)}$

$$
\pi=\left(\frac{a^{1-\sigma}}{\Delta} E+\frac{\phi a^{1-\sigma}}{\Delta^{*}} E^{*}\right) \frac{1}{\sigma}, \pi^{*}=\left(\frac{\phi a^{1-\sigma}}{\Delta} E+\frac{a^{1-\sigma}}{\Delta^{*}} E^{*}\right) \frac{1}{\sigma} .
$$

Because our model has asymmetric market size, $E(=s)>E^{*}(=1-s)$ (i.e., $\left.s>1 / 2\right)$, the pure profit of a North-based firm is greater than that of a South-based firm with positive trade costs. Therefore, allowing for free relocation, the pure profits are equalized and then firm shares, $n$, are determined as locational equilibrium:

$$
\pi-\pi^{*}=a^{1-\sigma} \frac{1-\phi}{\sigma}\left(\frac{s}{\Delta}-\frac{1-s}{\Delta}\right)=0 .
$$

Solving (6) for $n$, we obtain

$$
n=\frac{1}{2}+\left(\frac{1+\phi}{1-\phi}\right)\left(s-\frac{1}{2}\right) \text {. }
$$

As trade costs fall (as $\phi$ rises), $n$ increases and more South firms go to North, which is a socalled gradual agglomeration. Then, below a certain trade cost, called the sustain point ( $\phi=(1$ $-s) / s$, all firms concentrate in North, i.e., full agglomeration. That is, trade costs measured in terms of $\phi$ which are above the sustain point create full agglomeration in North as a stable equilibrium.

In the following analysis, we assume for simplicity that the initial equilibrium before

15) This normalization is not crucial for our main results. Even if we do not employ this normalization, all main results remain valid.

16) Note that each firm's profit is $1 / \sigma$ times firm revenue. The $(1-1 / \sigma)$ terms cancel out in the price of a variety and in CES composition. 
Greenhouse-gas Emission Controls and International Carbon Leakage through Trade Liberalization

introducing environmental policies is full agglomeration in North. Accordingly, trade costs discussed in our paper are assumed to be from the sustain point through free trade:

$$
(1-s) / s<\phi<1 \text {. }
$$

Emissions in the initial equilibrium without any environmental regulation (full agglomeration in North) can be written as

$$
G^{W}=G=\frac{a^{-\sigma}}{a^{1-\sigma}}=\frac{1}{a} \equiv G_{0}^{W},
$$

because $\Delta=a^{1-\sigma}$ and $\Delta^{*}=\phi \Delta$. Note that GHGs are initially emitted only in North because of full agglomeration in North, and the emissions are constant and independent of trade costs. More generally, as long as all firms concentrate in one country, either North or South, the amount of emissions is constant. If all firms are forced to relocate to South, global emissions become $G^{W}=G^{*}=\left(\phi \frac{s}{\Delta}+\frac{1-s}{\Delta^{*}}\right) a^{-\sigma}=\left(\frac{1}{\Delta^{*}}\right) a^{-\sigma}=\frac{1}{a}$, which equals those with full agglomeration in North. Hence, the global level of emissions is independent of location in the case of full agglomeration.

Lemma 1: Under full agglomeration without any environmental policy, the total amount of emissions is independent of trade costs and location of agglomeration.

\section{Emission Tax}

\subsection{Taxation without relocation}

Now we introduce environmental policies. Because of an international environmental agreement such as the Kyoto Protocol, an industrialized country, which has manufacturing agglomeration, namely North, sets a maximum level of emissions. To attain that level, we assume that North introduces either an emission tax or quota. In this section, we examine emission taxes.

Starting from full agglomeration, North sets an emission tax so as to reduce emissions and implement the international agreement. At this moment, relocation is prohibited (infinite relocation costs). Because one unit of GHG emissions corresponds to one unit of quantity produced in our model, an emission tax needs to be levied on each unit of production rather than prices, pure profits or sales. Thus, the emission tax is equivalent to a specific production tax, $t$. Then the total costs and prices are expressed as:

$$
T C_{j}=\pi+(a+t) x_{j} \text { and } p=\frac{a+t}{1-1 / \sigma} ; p^{*}=\frac{\tau(a+t)}{1-1 / \sigma} .
$$

The tax increases total costs and prices. ${ }^{17)}$ Thus, the pure profit of a North-based firm and the North's emissions without relocation are given by:

$$
\pi=\left(\frac{s}{\Delta}+\frac{\phi(1-s)}{\Delta^{*}}\right) \frac{(a+t)^{1-\sigma}}{\sigma}=\frac{\mu}{\sigma},
$$

17) Note that we assume $a+t<1$. 


$$
G^{W}=G=\left(\frac{s}{\Delta}+\frac{\phi(1-s)}{\Delta^{*}}\right)(a+t)^{-\sigma}=\frac{1}{a+t} \equiv G_{t}^{W},
$$

where North's full agglomeration leads to $\Delta=(a+t)^{1-\sigma}$ and $\Delta^{*}=\phi(a+t)^{1-\sigma}$. Note that taxation without relocation, i.e., without pollution haven, results in reducing emissions from $1 /$ $a$ to $1 /(a+t)$.

\subsection{Equilibrium with free relocation}

We now allow for free firm relocation. Because taxation decreases profits in North, firms may have incentive to move to the non-taxed country, i.e., South, regardless of its small market size. When tax rates are set at a substantial level such that $\pi<\pi^{*}$, i.e., $\left(\frac{a+t}{a}\right)^{1-\sigma}<$ $\phi_{s}+\frac{1-s}{\phi}$, full agglomeration is no longer stable and some firms relocate to South. Firm share, $n$, is determined so as to equalize pure profits between countries:

$$
\pi-\pi^{*}=\frac{1}{\sigma}\left(\frac{s}{\Delta}+\frac{\phi(1-s)}{\Delta^{*}}\right)(a+t)^{1-\sigma}-\frac{1}{\sigma}\left(\phi \frac{s}{\Delta}+\frac{1-s}{\Delta^{*}}\right) a^{1-\sigma}=0,
$$

where $\Delta=n a^{1-\sigma}+(1-n) \phi(a+t)^{1-\sigma}$ and $\Delta^{*}=n \phi a^{1-\sigma}+(1-n)(a+t)^{1-\sigma}$.

Figure 1 plots firm share, $n$, in terms of freeness of trade $\phi$. Given a fixed, low tax rate, the firm share locus is hump-shaped. Taxation causes pollution haven: firm relocation occurs from North (taxed country) to South (non-taxed country). Stated differently, it is necessary to have intermediate levels of trade costs to keep full agglomeration, $\phi_{N L}<\phi<\phi_{N U}$, which can be written as:

$$
\begin{aligned}
& \phi_{N U}=\frac{(a+t)^{1-\sigma}+\sqrt{(a+t)^{2(1-\sigma)}-4 s(1-s) a^{2(1-\sigma)}}}{2 a^{1-\sigma} s}, \\
& \phi_{N L}=\frac{(a+t)^{1-\sigma}-\sqrt{(a+t)^{2(1-\sigma)}-4 s(1-s) a^{2(1-\sigma)}}}{2 a^{1-\sigma} s} .
\end{aligned}
$$

Conversely, given a fixed $\phi$, a low tax rate can sustain full agglomeration. The condition for the low tax rate is given by:

$$
(a+t)^{2(1-\sigma)}-4 s(1-s) a^{2(1-\sigma)}>0 \Leftrightarrow t<\tilde{t} \equiv a(4 s(1-s))^{1 /(2(1-\sigma))}-a .
$$

When the tax rate is above $\tilde{t}$, North never sustains full agglomeration for any trade cost and instead at least one firm locates in South. Figure 2 illustrates the case of high tax rates without North's full agglomeration.

As shown in Figures 1 and 2, all firms relocate to South with a sufficiently small trade cost. This is called complete pollution haven which is defined as relocation of all firms from North to South. The critical value of trade costs, $\phi_{S}$, is analytically given by:

$$
\phi_{S}=\frac{a^{1-\sigma}-\sqrt{a^{2(1-\sigma)}-4 s(1-s)(a+t)^{2(1-\sigma)}}}{2 a^{1-\sigma}(1-s)} .
$$




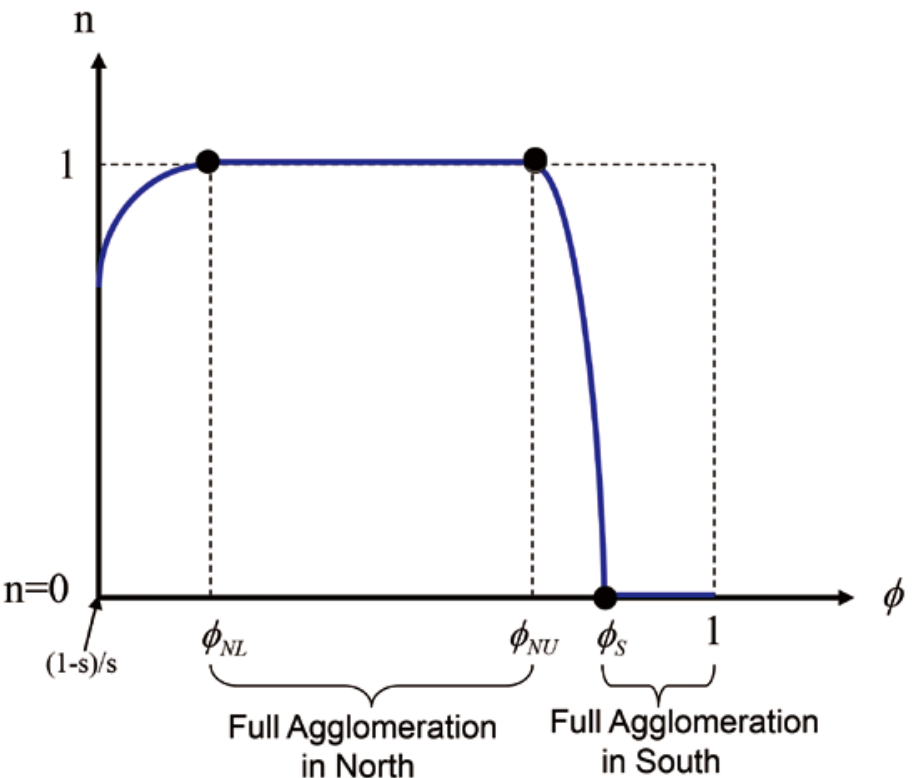

Figure 1: Tax and Firm Share

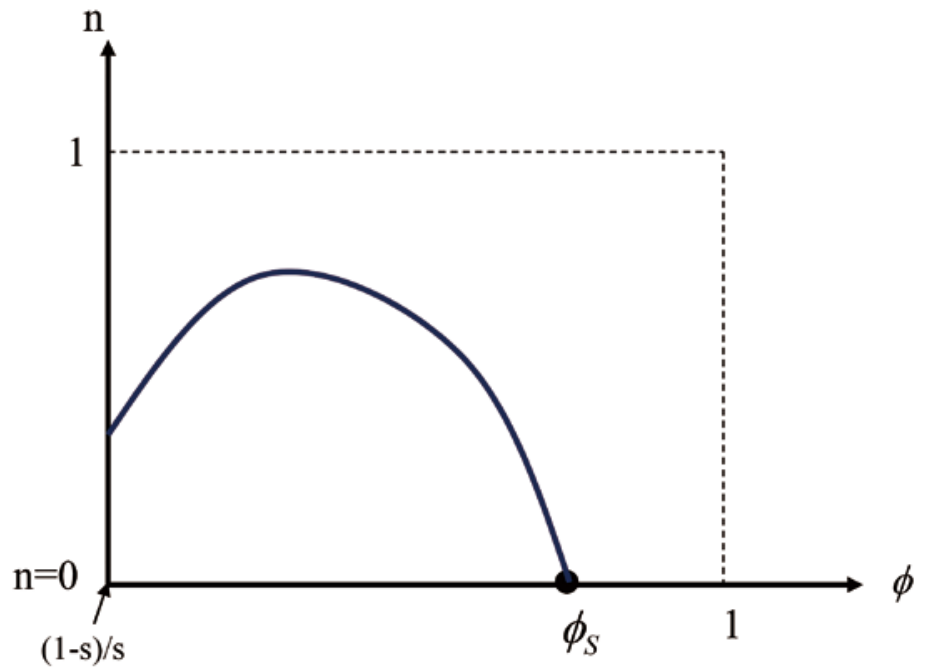

Figure 2: Tax and Firm Share (High Tax Rates)

As the tax rate, $t$, rises, the critical value, $\phi_{S}$, decreases and full agglomeration in South is more likely to occur. A sufficiently small trade cost coupled with a high tax rate accelerates pollution haven, relocating to the country without environmental regulation. Note that $\phi_{S}>$ $\phi_{N U}>\phi_{N L}$ is always ensured. ${ }^{18)}$ We can also verify that $\phi_{S}$ is always larger than $\phi_{N U}{ }^{19)}$

18) $\phi_{S}$ is a real number, because $a^{2(1-\sigma)}-4 s(1-s)(a+t)^{2(1-\sigma)}>0$.

19) This is because $4(1-s) s<1$ for $s>1 / 2$ and $a^{2(1-\sigma)}>(a+t)^{2(1-\sigma)}$. 
Proposition 1: When $\boldsymbol{t} \leq \tilde{\boldsymbol{t}}$, an emission tax leads North firms to relocate to South and causes pollution haven if $\phi>\phi_{N U}$ or if $\phi<\phi_{N L}$. When $t>t$, an emission tax necessarily results in firm relocation and hence pollution haven. Complete pollution haven occurs if $\phi>\phi_{S}$.

Interestingly, with large trade costs (i.e., $\left.(1-s) / s<\phi<\phi_{N L}\right)$, relocation is mitigated as trade costs fall. Note that the standard FC model (without any taxation) has hump-shaped agglomeration rents, which are a net benefit from agglomeration (see Baldwin et al., 2003, p. 81): when trade costs decrease, the rents first rise and then fall, and free trade generates no agglomeration rents. Taxation on the rents reduces the net benefit from agglomeration. Thus, both large and small trade costs lead to a negative net agglomeration benefit, which causes firm relocation to South.

Turning to emission levels, Figures 3 and 4 plot them for North, South and the world, which are given by:

$$
\begin{aligned}
& G=n\left(\frac{s}{\Delta}+\phi \frac{1-s}{\Delta^{*}}\right)(a+t)^{-\sigma} \equiv G_{T}, \\
& G^{*}=n^{*}\left(\phi \frac{s}{\Delta}+\frac{1-s}{\Delta^{*}}\right) a^{-\sigma} \equiv G_{T}^{*}, \\
& G^{W}=G+G^{*}=n\left(\frac{s}{\Delta}+\frac{\phi(1-s)}{\Delta^{*}}\right)(a+t)^{-\sigma}+n^{*}\left(\phi \frac{s}{\Delta}+\frac{1-s}{\Delta^{*}}\right) a^{-\sigma} \equiv G_{T}^{W},
\end{aligned}
$$

where $\Delta=n a^{1-\sigma}+(1-n) \phi(a+t)^{1-\sigma}$ and $\Delta^{*}=n \phi a^{1-\sigma}+(1-n)(a+t)^{1-\sigma}$.

Allowing firm relocation entails more GHG emissions than the target of the international agreement, $1 /(a+t)$, because pollution haven arises when trade costs are large or small. That is, when trade costs are large or small, a tax makes North's emissions smaller and South's emissions larger (Figure 3). The pollution haven decreases North's emissions, which are less than the target, $1 /(a+t)$, and increases South's emissions, which reach a maximum of $1 / a$ with South's full agglomeration:

$$
G^{W}=G^{*}=n^{*}\left(\phi \frac{s}{\Delta}+\frac{1-s}{\Delta^{*}}\right) a^{-\sigma}=\frac{1}{a}=G_{0}^{W},
$$

where $\Delta=\phi \Delta^{*}$ and $n^{*}=1$. Note that South's emissions exceed North's for certain levels of $\phi$. As trade costs fall given an emission in North, firm relocation decreases $n$ and then, when $n<\frac{a+t}{2 a+t}$ holds, the South's emissions exceed the North's.

Figure 4 shows global emissions, which are the sum of North's and South's emissions. When trade costs are small or large, global emissions increase. In particular, above $\phi_{S}$ all firms concentrate in South and no firms pay tax, and hence the emission level becomes $1 / a$, which is identical to the level without any environmental regulation (recall Lemma 1). North's emission policy is nullified and the global amount of emissions returns to the initial equilibrium (without environmental policy). We can say that the only impact of taxation with small trade costs is to transfer GHG emissions from North to South through the relocation of all firms. With small trade costs, unilateral emission taxation results in complete pollution haven i.e., full agglomeration in South) and taxation cannot control pollution any more. 


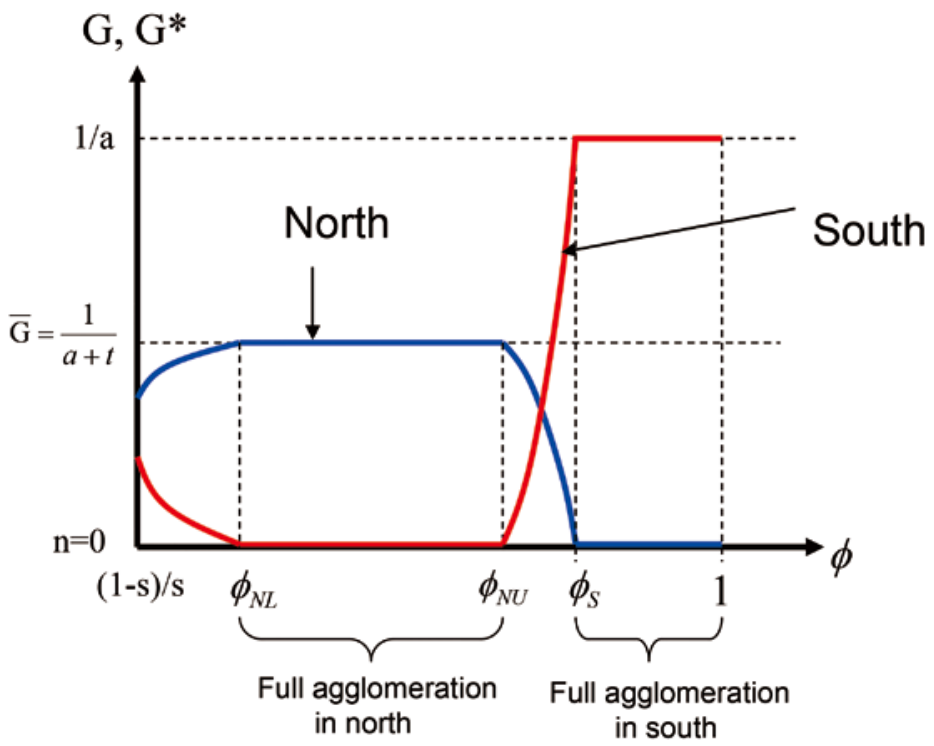

Figure 3: Local Emission Levels (Tax)

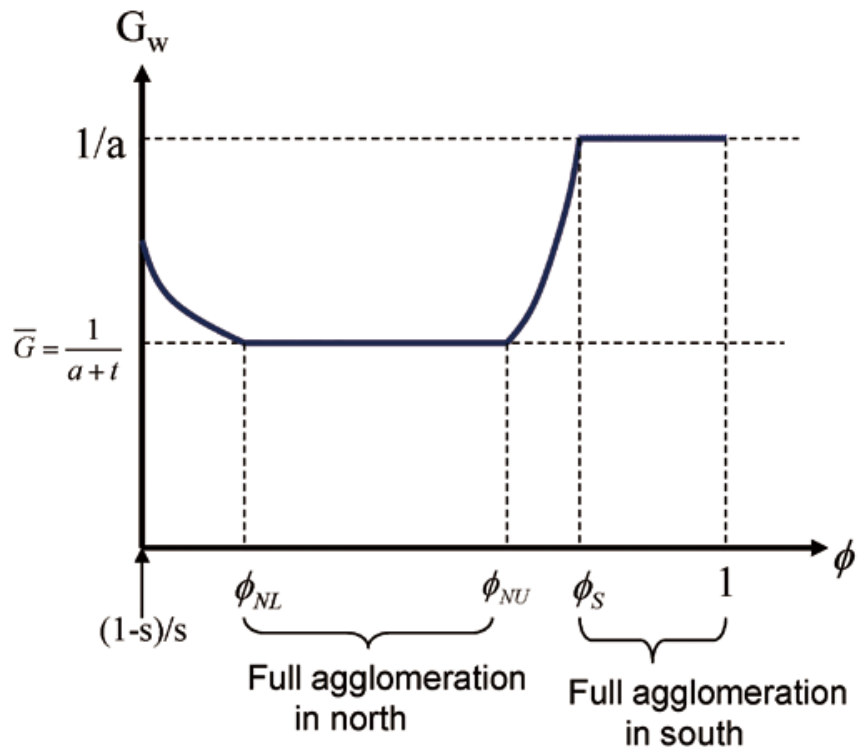

Figure 4: Global Emissions (Tax)

Proposition 2: With an emission tax in North, the global emission level is generally U-shaped in terms of trade freeness. Emission taxation has no impact on the global emission level when trade costs are sufficiently small (i.e., $\phi>\phi_{S}$ ). 


\section{Emission Quota}

\subsection{Quota without relocation}

Next we discuss the other policy, an emission quota. In this case, starting from full agglomeration, North unilaterally introduces an emission quota so as to satisfy the international environmental agreement. To make a strict comparison with the policy impact on pollution haven in the tax case, the quota is set so that the emission level under the quota is the same as that under taxation at the initial equilibrium (North's full agglomeration), i.e., $\bar{G} \equiv \frac{1}{a+t}$ (constant). We call this quota "the tax-equivalent quota". Moreover, the quota is assumed to be accompanied by creation of a competitive emission-permit market in North. The quota is implemented by the North government via a fee. Purchasing one unit of the permit allows one unit of production for a North firm. Using (8), the level of the quota is given by:

$$
\bar{G}=\left(\frac{s}{(a+\bar{q})^{1-\sigma}}+\frac{1-s}{(a+\bar{q})^{1-\sigma}}\right)(a+\bar{q})^{-\sigma}=\frac{1}{a+\bar{q}}=\frac{1}{a+t}=G_{t}^{W} .
$$

Thus, the price of emission permit $q$ is equal to $t$ with full agglomeration, i.e., $\bar{q}=t$.

The following should be noted. Although tax rates are exogenously determined by an international agreement, the price of permit, $q$, is endogenously determined by the number of firms located in North and trade costs so as to clear North's emission-permit market:

$$
n\left(\frac{s}{\Delta}+\frac{\phi(1-s)}{\Delta^{*}}\right)(a+q)^{-\sigma}-\bar{G}=0
$$

where $\Delta=n a^{1-\sigma}+(1-n) \phi(a+q)^{1-\sigma}$ and $\Delta^{*}=n \phi a^{1-\sigma}+(1-n)(a+q)^{1-\sigma}$.

This results in different impacts on firm location and emission level. Total costs and prices are given by $T C=\pi+(a+q) x, p=\frac{a+q}{1-1 / \sigma}$ and $p^{*}=\frac{\tau(a+q)}{1-1 / \sigma}$. Firm location is determined by profit equalization and the size of the quota.

\subsection{Equilibrium with free relocation}

In the equilibrium with free relocation, $n$ and $q$ are determined by pure profit equalization as well as the emission constraint: ${ }^{20)}$

$$
\begin{aligned}
& \pi-\pi^{*}=\frac{1}{\sigma}\left(\frac{s}{\Delta}+\frac{\phi(1-s)}{\Delta^{*}}\right)(a+q)^{1-\sigma}-\frac{1}{\sigma}\left(\phi \frac{s}{\Delta}+\frac{1-s}{\Delta^{*}}\right) a^{1-\sigma}=0, \\
& n\left(\frac{s}{\Delta}+\frac{\phi(1-s)}{\Delta^{*}}\right)(a+q)^{-\sigma}=\bar{G},
\end{aligned}
$$

where $\Delta=n a^{1-\sigma}+(1-n) \phi(a+q)^{1-\sigma}$ and $\Delta^{*}=n \phi a^{1-\sigma}+(1-n)(a+q)^{1-\sigma}$.

Figure 5 plots firm share, $n$, in terms of freeness of trade, $\phi$. Similarly to the case of emission taxes, small or large trade costs lead to firm relocation and pollution haven, while

20) In our model, the quota is always binding and has a positive permit price. If $q$ is zero, then no firm has an incentive to relocate to South. 


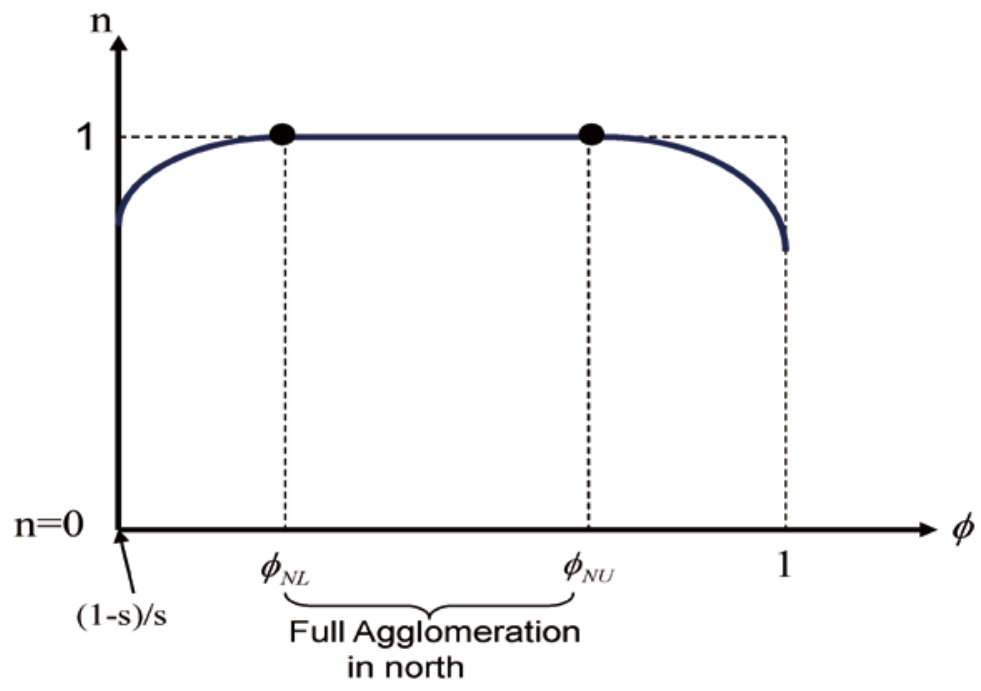

Figure 5: Quota and Firm Share

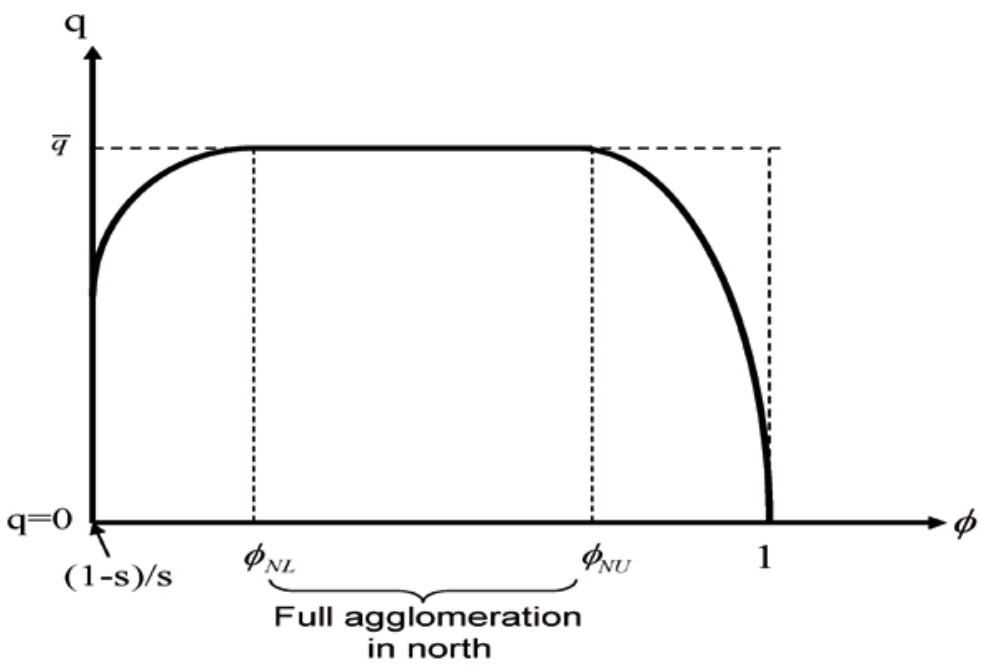

Figure 6: Quota Prices

intermediate trade costs can sustain full agglomeration in North.

Because we assume that the emission level under a quota is the same with that under taxation with full agglomeration, $\bar{q}=t$ and trade costs that result in full agglomeration are equivalent to those under taxation:

$$
\phi_{N U}=\frac{(a+\bar{q})^{1-\sigma}+\sqrt{(a+\bar{q})^{2(1-\sigma)}-4 s(1-s) a^{2(1-\sigma)}}}{2 a^{1-\sigma} S},
$$




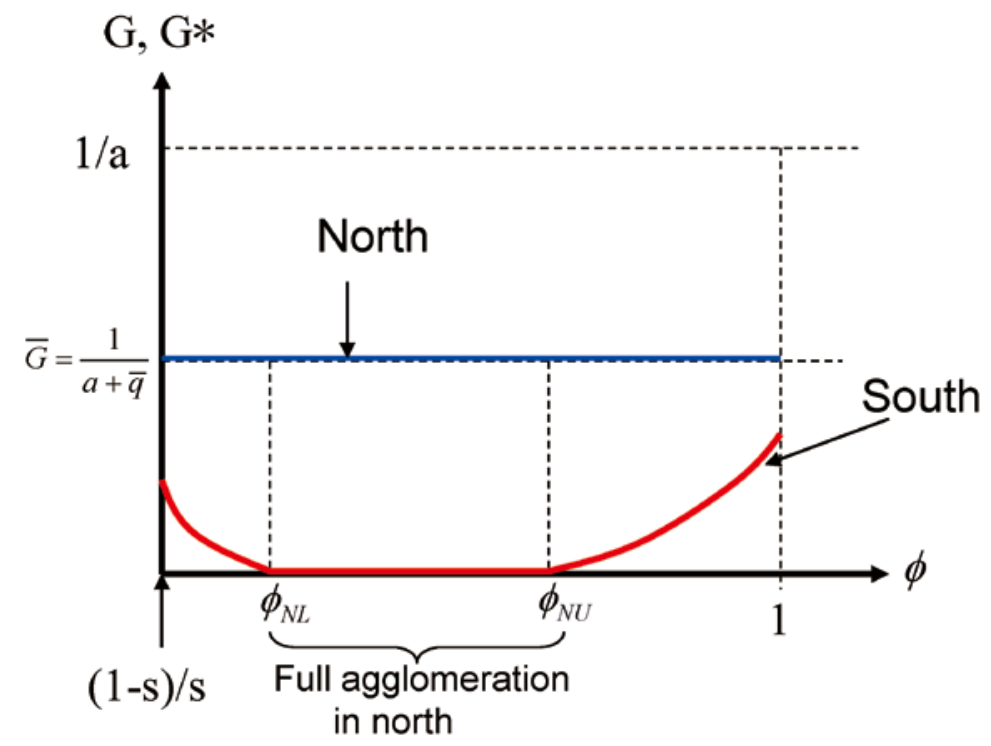

Figure 7: Local Emission Levels (Quota)

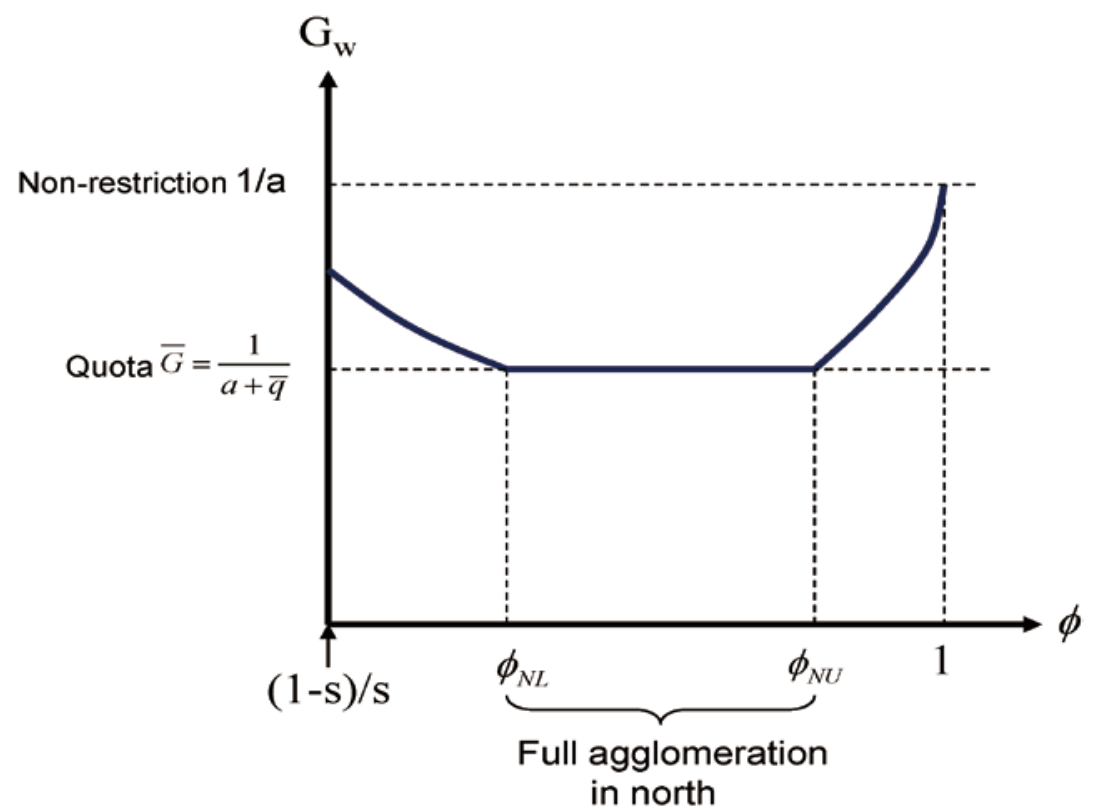

Figure 8: Global Emissions (Quota)

$\phi_{N L}=\frac{(a+\bar{q})^{1-\sigma}-\sqrt{(a+\bar{q})^{2(1-\sigma)}-4 s(1-s) a^{2(1-\sigma)}}}{2 a^{1-\sigma} s}$.

However, unlike the effect of an emission tax, a quota does not involve South's full 
agglomeration with small trade costs. Some firms stay in North at any trade cost.

As plotted in Figure 6, $q$ is positive for $0 \leq \phi<1$ and hump-shaped. As long as all firms are in North (i.e., full agglomeration in North) with intermediate trade costs, quota prices equal the values of $t(=\bar{q})$. Firm relocation to South reduces $q$, but the tax rate $t$ remains constant. Firm relocation to South softens the quota constraint in North. The fall of the permit price reduces the disadvantage of locating in North and mitigates relocation.

Proposition 3: When $\bar{G} \geq 1 /(a+\tilde{\boldsymbol{t}})$, an emission quota leads to pollution haven if $\phi>\phi_{N U}$ or if $\phi<\phi_{N U}$. When $\bar{G}<1 /(a+\tilde{t})$, an emission quota necessarily results in pollution haven. However, complete pollution haven (i.e., full agglomeration in South) never occurs for any positive quota level.

Emission levels in North, South, and the world are, respectively, given by:

$$
\begin{aligned}
& G=n\left(\frac{s}{\Delta}+\phi \frac{1-s}{\Delta^{*}}\right)(a+q)^{-\sigma}=\bar{G}=\frac{1}{a+t},(\text { constant }) \\
& G^{*}=n^{*}\left(\phi \frac{s}{\Delta}+\frac{1-s}{\Delta^{*}}\right) a^{-\sigma} \equiv G_{Q}^{*}, \\
& G^{W}=G+G^{*}=\frac{1}{a+t}+n^{*}\left(\phi \frac{s}{\Delta}+\frac{1-s}{\Delta^{*}}\right) a^{-\sigma} \equiv G_{Q}^{W} .
\end{aligned}
$$

Figures 7 and 8 plot emissions in terms of trade costs. As in the tax case, a quota leads to U-shaped global emissions in terms of trade costs. More generally, in the case of small/large trade costs, some firms relocate and emit GHGs in South, though North's emissions are at 1/ $(a+t)$ because of the emission constraint. However, unlike the effect of taxation, global emissions never return to the level without emission regulations, $1 / a$, for any positive trade costs. Because South never creates full agglomeration and the quota is still binding in North, this diversification of firm location results in less global emissions than the case without any policy as well as the case of taxation.

Proposition 4: In the case of emission quotas, North's GHG emissions are always at the target level, though trade liberalization decreases South's emissions if trade costs are large (i.e., $\left.(1-s) / s<\phi<\phi_{N L}\right)$ but increases South's emissions if trade costs are small (i.e., $\left.\phi>\phi_{N U}\right)$.

\section{Emission Tax versus Quota}

In this section, we compare the two policies from the viewpoint of emissions. The first finding is related to the tax rate and the quota price. Because an international agreement allocates a certain amount of GHG emissions to North, $\bar{G}$, the tax rate equals the permit price in the quota system (i.e., $t=\bar{q}$ ) as long as all firms concentrate in North. For this reason, both policies have the same full agglomeration range: the same levels of $\phi_{N L}$ and $\phi_{N U}$. This implies that firm relocation begins at the same critical trade costs. However, relocation to South caused by environmental regulations results in $q$ being less than $t$ for a given $\phi$ (i.e., $t>q$ ) (see Appendix "quota price and tax rate" for an analytical derivation). The tax rate is fixed, but the price of the emission permit is endogenously determined by the number of North firms. As more firms relocate to South, the emission constraint can be more easily attained and the per- 


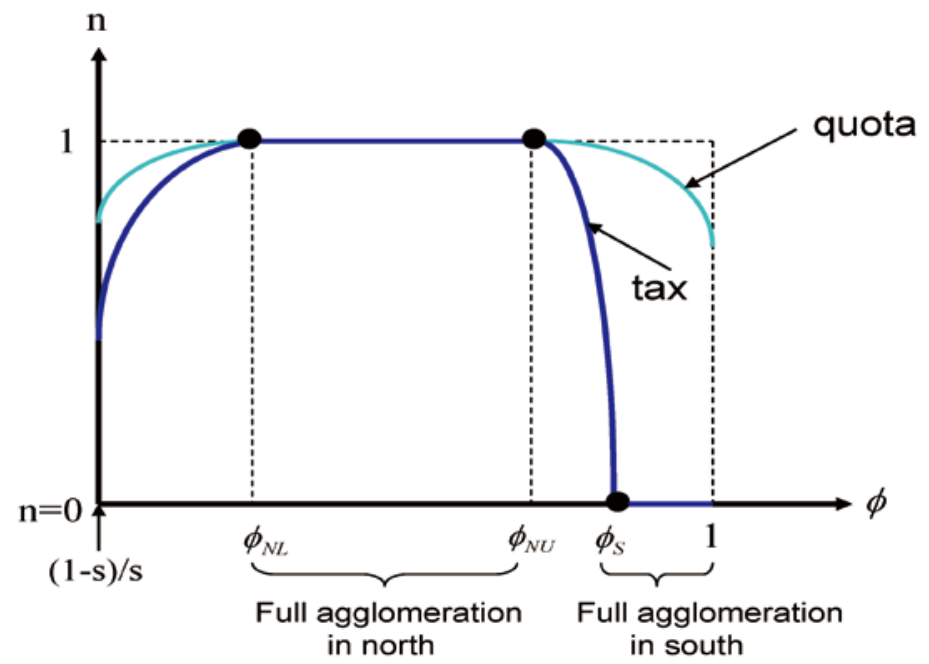

Figure 9: Firm Share (Tax and Quota)

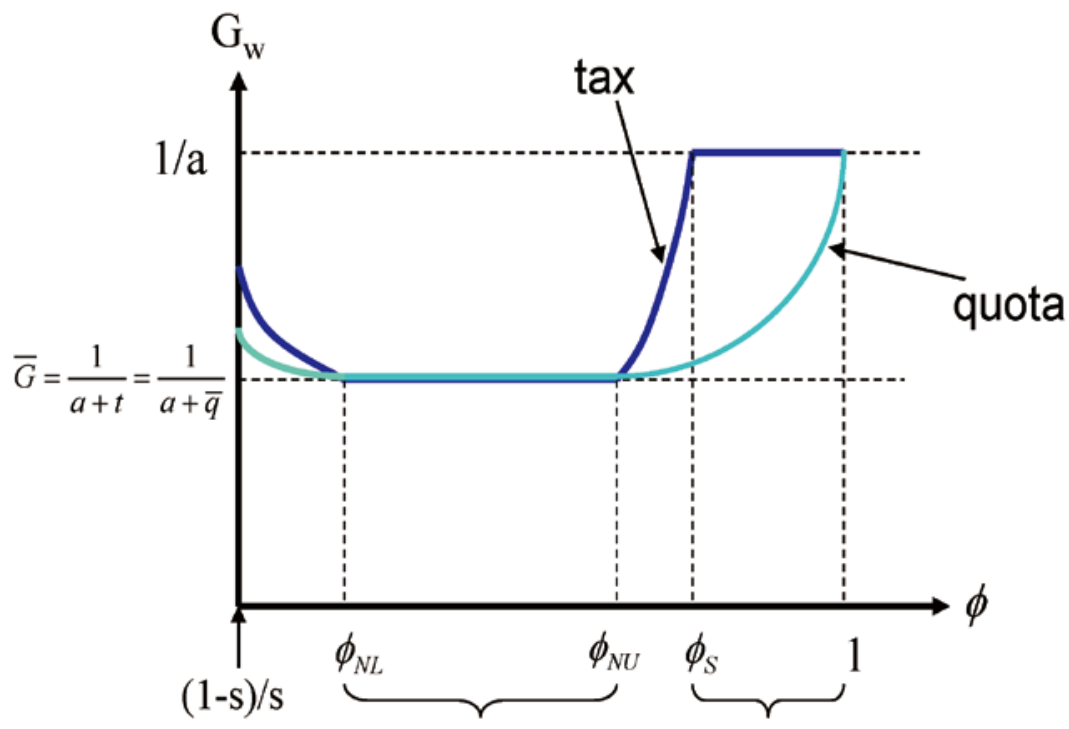

Full agglomeration Full agglomeration

in north in south

Figure 10: Global Emissions (Tax and Quota)

mit price decreases, which hampers firm relocation. To summarize: ${ }^{21)}$

Proposition 5: Suppose that a tax-equivalent quota is introduced instead of an emission

21) This finding is somewhat similar to Krishna and Tan (2010), studying whether tariff and quota are equivalent under free entry and exit in a competitive setting. They find that tariff (tax) and quota are not equivalent, because quota discourages entry less than tariff (tax) through the adjustment of quota prices. However, their model is completely different from ours. 
tax. In the presence of relocation, the price of the emission permit is always lower than the emission tax rate.

In other words, the quota has a weaker relocation force than does the tax. As is clear in Figure 9, pollution haven is moderate under the quota. Because the tax has a stronger relocation effect, it always leads to more pollution haven and full agglomeration in South is possible. This implies that in the presence of pollution haven, the emissions in North are greater with a tax-equivalent quota than with taxation for given $\phi$ (see Appendix "North's emission level under tax and quota" for derivation). Turning to global emissions, however, they are less with a tax-equivalent quota than with taxation for given $\phi$.

Proposition 6: Compared with taxation, a tax-equivalent quota can mitigate pollution haven. In the presence of pollution haven, the GHG emissions in North are higher but the global emissions are lower with the tax-equivalent quota.

One of our key assumptions is a fixed tax rate and an endogenous quota price influenced by firm location patterns and trade costs. This leads to contrasting results in trade liberalization. One may think that the North government may revise tax rates as trade costs fall. If this is the case, the North government can set tax rates equal to quota prices and the two instruments become equivalent. However, a government is less likely to revise tax rates so frequently. From the viewpoint of global emissions, therefore, an emission tax compares unfavourably with an emission quota based on market mechanism.

\section{Conclusion}

This paper has studied the impact of environmental policies on firm location and pollution haven when an international agreement such as the Kyoto Protocol requires the ratified countries (i.e., North) to reduce emissions by a certain amount. We have specifically compared two environmental policy tools, emission taxes and quotas, under trade liberalization.

Either environmental policy could lead firms to relocate to countries without any environmental regulation (i.e., South), which causes international carbon leakage. An interesting result is that the leakage is $\mathrm{U}$-shaped in trade freeness. In the presence of firm relocation, a fall in trade costs reduces the leakage when trade costs are high, and vice versa when trade costs are low. Therefore, when an environmental agreement is ratified by North alone, trade liberalization could initially decrease the global emissions, but eventually increase them. The relationship between trade liberalization and global emissions is non-monotonic. This implies that under trade liberalization, both North and South should commit themselves to reducing their GHG emissions to deal with global warming.

It has also been shown that an emission tax results in more firm relocation than an emission quota based on market mechanism. Therefore, an emission tax causes more pollution haven, increasing global emissions. This implies that when South hesitates to regulate its emissions (which has been observed), endogenizing environmental policy in North is a more plausible approach to considering the environmental consequences of trade liberalization.

In concluding this paper, four final remarks are in order. First, to focus on firm relocation, we have adopted the simplest trade and geography model in which firm locations and trade costs are central issues. Also the agglomeration rent plays a crucial role in our result. It is certainly worthwhile to examine the robustness of our verdicts within other frameworks. One 
may naturally think that an alternative is the HO framework. Without firm relocation, we can construct and analyze a two-factor, two-good HO model where two factors are labor and emissions (e.g. Copeland and Taylor, 2005; Ishikawa and Kiyono, 2006; Ishikawa et al., 2012). However, we need another factor, capital, when exploring firm relocation. As is well known, it is messy to handle capital movements in a three-factor, two-good HO model.

Second, one of our key assumptions is that the emission tax rate is constant even if trade liberalization promotes firm relocation. This assumption should be distinguished from an implication obtained in the theoretical literature of tax competition (such as Baldwin and Krugman, 2004) that tax rates should be adjusted to prevent firms from relocating abroad and maximize tax revenue. Typically, taxes are lowered under globalization. ${ }^{22)}$ We should mention that the objective of government policy in our analysis is different from tax revenue maximization. The North government is required to reduce GHG emissions to satisfy an international environmental agreement. One of our main focuses is to compare between emission taxes and quotas. While the permit price is endogenously determined by firm location choice, the tax rate is exogenously given. To highlight the difference between the endogenous fees for emissions and the exogenous ones, we adopt a constant tax rate.

Third, the policy target in this paper is to reduce GHG emissions to highlight the different policy effects of taxes and quotas. Of course, it is plausible to think that governments maximize social welfare. Welfare analysis and socially optimal policies are left for future research. Because our model assumes one unit of emission per unit of quantity produced, production and emissions are subject to the perfect trade-off: more production (consumption) positively affects welfare but simultaneously has a negative effect through increased emissions. There may exist an optimal level of emissions and production, which hinges on the specification of a social welfare function. To conduct welfare analysis formally, we have to specify disutility in the utility function more rigorously, taking account of accumulation of emissions over time. Furthermore, it would be worthwhile to consider the negative impact of emissions on A-sector productivity. A-sector may be subject to decreasing returns to scale by serious emissions.

Lastly, we have assumed a quasi-linear utility function that excludes an income effect. The total demand for manufactured goods remains constant even if firms relocate and prices change. The constant total demand implies constant total production and hence the global emission level without any environmental policy is independent of trade costs. This has the advantage of highlighting the different effects of the two policies. We can get analytical solutions allowing us to easily compare the relocation effects of taxes and quotas. Furthermore, even if we take into account tax/quota-revenue reimbursement, because we can ignore its impact, we can narrow our focus on the effects of each policy scheme to include only firm location and pollution haven. However, it is certainly worthwhile examining the robustness of our results in the presence of an income effect. The presence of an income effect caused by relocation may cause complete specialization in manufacturing in South and in agriculture in North, though it is an extreme and unrealistic case. In this case, factor prices are determined by the trade balance and factor markets; and market size and factor prices may determine

22) Most of empirical studies find that globalization raises corporate tax rates, which contradicts to theoretical predictions (e.g. Garrett, 1995; Quinn, 1997; Swank, 1998). 
Greenhouse-gas Emission Controls and International Carbon Leakage through Trade Liberalization

emission levels.

\section{Appendix: Quota and Tax}

In this appendix, we mathematically show the relationship between tax and quota policies using analytical solutions. North's emissions without relocation, which are the target of an international agreement, are:

$$
G_{t}=\frac{1}{a+t}=\left(\frac{s}{\bar{\Delta}}+\phi \frac{1-s}{\bar{\Delta}^{*}}\right)(a+t)^{-\sigma},
$$

where $\bar{\Delta}=(a+t)^{1-\sigma}$ and $\bar{\Delta}^{*}=\phi \bar{\Delta}$. As mentioned in the main text, this target level of emissions always corresponds to that of the quota case, regardless of relocation:

$$
\bar{G}=G_{t}=\frac{1}{a+t}=\frac{1}{a+\bar{q}} .
$$

Note that at an initial equilibrium (full agglomeration without allowing for relocation), $q$ is equal to $t(\bar{q}=t)$.

\section{North's emission level under tax and quota}

Next, allowing for relocation, North's emissions under tax policy can be written as:

$$
G_{T}=n\left(\frac{s}{\Delta}+\phi \frac{1-s}{\Delta^{*}}\right)(a+t)^{-\sigma},
$$

where tax rate $t$ is fixed. We compare (A1) with (A2):

$$
\begin{aligned}
& \frac{\Delta}{n}=(a+t)^{1-\sigma}+\frac{1-n}{n} \phi a^{1-\sigma} \geq \bar{\Delta}=(a+t)^{1-\sigma}, \\
& \frac{\Delta^{*}}{n}=\phi(a+t)^{1-\sigma}+\frac{1-n}{n} a^{1-\sigma} \geq \bar{\Delta}^{*}=\phi(a+t)^{1-\sigma} .
\end{aligned}
$$

Therefore, North's emission level under the tax-equivalent quota is higher than under the tax for any trade costs, $G_{Q} \geq G_{T}$.

\section{Quota price and tax rate}

Turning to $q$, because North's emissions are always identical to the target in the international agreements, by keeping a constant emission level through adjusting quota prices, North's emissions under free relocation are binding (13).

$$
\bar{G}=\frac{1}{a+t}=n\left(\frac{s}{\Delta}+\phi \frac{1-s}{\Delta^{*}}\right)(a+q)^{-\sigma} .
$$

The quota-market clearing condition can be rewritten as:

$$
\frac{1}{a+t}-\left(\frac{s}{(a+q)+\frac{\phi(1-n) a^{1-\sigma}}{n(a+q)^{-\sigma}}}+\frac{1-s}{(a+q)+\frac{(1-n) a^{1-\sigma}}{n \phi(a+q)^{-\sigma}}}\right)=0 .
$$


To satisfy the condition, we need $q \leq t$ because $\frac{\phi(1-n) a^{1-\sigma}}{n(a+q)^{-\sigma}} \geq 0$ and $\frac{(1-n) a^{1-\sigma}}{\phi n(a+q)^{-\sigma}} \geq 0$.

Therefore, we show that the endogenously determined quota price is always lower than the tax rate, given the same emission target in North.

\section{References}

Baldwin, R., R. Forslid, P. Martin, G. Ottaviano and F. Robert-Nicoud (2003) Economic Geography and Public Policy, Princeton University Press, Princeton.

Baldwin, R.E. and P. Krugman (2004) “Agglomeration, Integration and Tax Harmonisation," European Economic Review 48, 1-23.

Becker, R. and V. Henderson (2000) "Effects of Air Quality Regulations on Polluting Industries," Journal of Political Economy 108, 379-421.

Burniaux, J. and J.O. Martins (2000) “Carbon Emission Leakages: A General Equilibrium View," OECD Economics Department Working Papers, No. 242, OECD Publishing.

Cole, M.A., R.J.R. Elliott and T. Okubo (2010) "Trade, Environmental Regulations and Industrial Mobility: An Industry-Level Study of Japan,” Ecological Economics 69, 1995-2002.

Copeland, B. and M.S. Taylor (2005) "Free Trade and Global Warming: a Trade Theory View of the Kyoto Protocol," Journal of Environmental Economics and Management 49, 205-234.

Ederington, J., A. Levinson and J. Minier (2005) "Footloose and Pollution-Free," Review of Economics and Statistics 87, 92-99.

Elbers, C. and C. Withagen (2004) "Environmental Policy, Population Dynamics and Agglomeration," Contributions to Economic Analysis \& Policy 3 (2), Article 3.

Felder, S. and T.F. Rutherford (1993) "Unilateral CO Reductions and Carbon Leakage: The Consequences of International Trade in Oil and Basic Materials," Journal of Environmental Economics and Management 25, 162-176.

Forslid, R., T. Okubo and M. Sanctuary (2013) “Trade, Transboundary Pollution and Market Size," CEPR Discussion Paper, 9412.

Garrett, G. (1995) "Capital mobility, trade and the domestic politics of economic policy," International Organization 49, 657-687.

Greenstone, M. (2002) "The Impacts of Environmental Regulations on Industrial Activity: Evidence from the 1970 and 1977 Clean Air Act Amendments and the Census of Manufactures," Journal of Political Economy 110, 1175-1219.

Henderson, J.V. (1996) "Effects of Air Quality Regulation," American Economic Review 86, 789-813.

Ishikawa, J. and K. Kiyono (2000) "International Trade and Global Warming," CIRJE Discussion Paper Series, CIRJE-F-78, Faculty of Economics, University of Tokyo.

Ishikawa, J. and K. Kiyono (2006) "Greenhouse-gas Emission Controls in an Open Economy," International Economic Review 47, 431-450.

Ishikawa, J., K. Kiyono and M. Yomogida (2012) “Is Emission Trading Beneficial ?," Japanese Economic Review 63, 185-203.

Ishikawa, J. and T. Okubo (2011) "Environmental Product Standards in North-South Trade," Review of Development Economics 15, 458-473.

Ishikawa, J. and T. Okubo (2016) "Greenhouse-Gas Emission Controls and Firm Locations in NorthSouth Trade", forthcoming in Environmental and Resource Economics

Jaffe, A.B., S.R. Peterson, P.R. Portney and R.N. Stavins (1995) "Environmental Regulations and the Competitiveness of U.S. Manufacturing: What does the Evidence Tell Us?," Journal of Economic Literature 33(1), 132-163.

Kind, H., K. Midelfart-Knarvik and G. Schjelderup (1998) "Industrial agglomeration and capital taxa- 
Greenhouse-gas Emission Controls and International Carbon Leakage through Trade Liberalization

tion," Norwegian School of Economics, Department of Economics, Discussion Paper 7/98.

Kiyono, K. and J. Ishikawa (2004) "Strategic Emission Tax-quota Non-equivalence under International Carbon Leakage," in H. Ursprung and S. Katayama (eds.) International Economic Policies in a Globalized World, Springer Verlag, 133-150.

Kiyono, K. and J. Ishikawa (2013) "Environmental Management Policy under International Carbon Leakage," International Economic Review 54, 1057-1083.

Krishna, K. and L.H. Tan (2010) "Trade Policy with Endogenous Entry Revisited," Journal of International Economics 80, 271-279.

Levinson, A. and M.S. Taylor (2008) "Unmasking the Pollution Haven Effect," International Economic Review 49, 223-254.

List, J.A., D.L. Millimet, P.G. Fredriksson and W.W. McHone (2003) "Effects of Environmental Regulations on Manufacturing Plant Births: Evidence from A Propensity Score Matching Estimator," Review of Economics and Statistics 85, 944-952.

Ludema, R. and I. Wooton (2000) "Economic geography and the fiscal effects of regional integration," Journal of International Economics 52(2), 331-357.

Markusen, J.R., E.R. Morey and N.D. Olewiler (1993) "Environmental policy when market structure and plant locations are endogenous," Journal of Environmental Economics and Management 24, 69-86.

Markusen, J.R., E.R. Morey and N.D. Olewiler (1995) "Competition in regional environmental policies when plant locations are endogenous," Journal of Public Economics 56, 55-77.

Martin, P. and C.A. Rogers (1995) "Industrial location and public infrastructure," Journal of International Economics 39, 335-351.

Pethig, R. (1976) "Pollution, welfare, and environmental policy in the theory of Comparative Advantage," Journal of Environmental Economics and Management 2, 160-169.

Pflüger, M. (2001) "Ecological dumping under monopolistic competition," Scandinavian Journal of Economics 103, 689-706.

Quinn, D. (1997) "The correlates of change in international financial regulation," American Political Science Review 91, 531-551.

Rauscher, M. (1995) "Environmental regulation and the location of polluting industries," International Tax and Public Finance 2, 229-244.

Smarzynska, J.B. and S. Wei (2004) "Pollution Havens and Foreign Direct Investment: Dirty Secret or Popular Myth?" Contributions to Economic Analysis \& Policy 3(2), Article 8.

Swank, D. (1998) "Funding the welfare state: globalisation and the taxation of business in advanced market economies," Political Studies, 671-692.

Ulph, A. and L. Valentini (2001) "Is environmental dumping greater when plants are footloose?" Scandinavian Journal of Economics 103, 673-688.

Venables, A.J. (2001) "Economic Policy and the Manufacturing base: hysteresis in location," in A. Ulph (ed.), Environmental Policy, International Agreements, and International Trade, OUP. 